\title{
Leadership and Ethics in Social Media
}

Abstract This chapter discusses leadership dimensions of social media ethics through the lens of theories about ethical leadership and balanced leadership. Informants within this study have reported about (1) insufficient support from leaders, who tend to have restricted understanding of the workings of social media; (2) a lack of established codes or norms; (3) an absence of narratives about exemplary handlings of previous cases; and (4) limited access to concepts and ideas to clarify the issues at stake. Categorization of ethical dilemmas that occur in connection with social media use can potentially bring employees and leaders closer together in a common understanding of the challenges. The Navigation Wheel and related principles can be helpful for thinking systematically about the alternatives at hand and in ethical debriefings. The chapter ends with a reflection on how ethics with regard to social media has a proscriptive (avoid harm) and prescriptive (do good) dimension.

Keywords Ethical leadership $\bullet$ Balanced leadership $\bullet$ Social media $\bullet$ Proscriptive ethics $\bullet$ Prescriptive ethics 
A bank wanted to reach out to younger people and asked two employees from that generation to come up with a humorous narrative that could be conveyed through photos on Instagram. The employees responded to the challenge by creating a story about a 23-year-old man who was using his credit card to live an active and adventurous life. They made a fictitious account on Instagram and posted photos of the credit card in various contexts. The young man used it in everyday situations, travelling and enjoying himself with friends. To get more attention, though, the narrative gradually became more controversial and daring. The young man attended a German Oktoberfest, where his credit card was photographed placed in the cleavage of a woman serving beer in a local costume. In his travel to Amsterdam, he was shown peeking through the window of a brothel, credit card in hand. Another photo showed the logo of a clinic known for treating sexually transmitted diseases. The story of the young credit card user was meant to be lighthearted, humorous and appealing to a younger generation of bank customers, but now negative reactions began to appear. Both older people and representatives of the target generation criticized the Instagram marketing for exhibiting sexism and male chauvinism. The most provocative photos were quickly deleted, and after a while, the bank terminated the story of the young credit card user.

The marketing director of the bank was one of the executive students who contributed to the categorization of digital dilemmas in this study. He explained in class how negative responses to the Instagram narrative put the leadership of the organization to the test. Clearly, the people responsible for the postings had gone too far and put the bank in a difficult situation. They had faced a tempo dilemma; how were they to keep up the intensity and pace of this particular story? In hindsight, their decision-making was ethically flawed. Put in Navigation Wheel terms, the Instagram story raised questions about the bank's identity and core values, creating a minor reputational crisis. This was an old, traditional organization associated with social responsibility and a stable set of values. From an ethical point of view, the posting of the photos was also questionable because they promoted a view of the female body as a commodity for rich men. However, the two employees had been given a scope of action for experimenting with and testing ideas in a high-tempo 
format. Leaders at the bank protected them from public criticism and took responsibility for any offense the campaign caused.

The final chapter of this book addresses social media ethics in relation to leadership. The use of social media in organizational contexts creates ethical challenges for leaders, as illustrated by the case of the Instagram postings described above. In that particular scenario, the leaders took responsibility and offered protection to employees who had overstepped the boundaries of ethical social media use. The input to this study indicates that this kind of ethically appropriate leadership in a social media context is rare. Leaders struggle to cope adequately in such situations, particularly if they are unfamiliar with the workings of social media.

The first section addresses how informants report on an absence of what research has labeled ethical leadership (Brown, Treviño, \& Harrison, 2005), that is, normatively appropriate conduct through personal actions and interpersonal relationships. The informants are professionals responsible for handling the social media platforms for their organizations. When they face ethical dilemmas, they seek ethical guidance and support from their leaders. In response, these leaders tend to expect the informants to be the experts, not only on the workings of social media but also on appropriate responses to ethically questionable behavior among colleagues or other ethical issues arising from social media use. Additionally, some informants report that the leaders themselves engage in unethical behavior on social media. An absence of ethical leadership thus appears to restrict social media professionals' ability to cope with ethical dilemmas at work.

The second section applies the concept of balanced leadership and explores how it can shed light on the tensions reported by informants in relation to leaders in their organizations. Balanced leadership derives from a combination of vertical leadership, which is an activity performed by one person overlooking and instructing processes in an organization, and horizontal leadership, which takes place between members of a team and alternates between them (Müller, Packendorff, \& Sankaran, 2017). Leaders with a restricted understanding of the nature of social media are ill equipped to exercise vertical leadership in the sense of offering support or guidance when ethical dilemmas appear. An organization can address this problem by creating opportunities for leaders to learn more about 
social media, by opening up horizontal leadership, whereunder the responsibility for taking initiatives and supporting colleagues lies with each member of the team, or by a combination of these options.

The final section of this chapter outlines how social media create ethical issues connected not only to the avoidance of negative behaviors and outcomes, but also to the promotion of positive ones. Familiarity with the distinction between do-good ethics and avoid-harm ethics in the realm of social media should belong to the vocabulary of leaders. Organizational ethics has a tendency to focus on the harmful aspects of agency and decision-making at the expense of the beneficial aspects. Ethics has largely been associated with the kinds of behaviors one should avoid, rather than those kinds one should practice to bring about positive change. The do not's have dominated over the do's and the should not's over the should's. Research has identified this asymmetry and called for more attention to the ethics of doing good (Janoff-Bulman, Sheikh, \& Hepp, 2009; Mayer, 2010; Treviño, Weaver, \& Reynolds, 2006). The current study ends with a reflection on how practitioners and researchers with an ethics orientation should have their eyes open to both the harmful and the beneficial aspects of social media.

\section{Ethical Leadership}

The concept of ethical leadership has been defined as a demonstration of normatively appropriate conduct through personal actions and interpersonal relationships, with an emphasis on the promotion of such conduct to followers through two-way communication, reinforcement and decision-making (Brown et al., 2005; Neubert, Carlson, Kacmar, Roberts, \& Chonko, 2009). In the opening example, the leaders in the bank appear to have responded to the ethical challenges connected to the provocative Instagram postings in an exemplary manner. They demonstrated normatively appropriate conduct by shielding from criticism the employees who had been given a scope of action for experimenting with the format.

The high tempo of social media increases the risk of making mistakes, which is a significant challenge for normatively appropriate leadership 
practices in the area. As noted in previous chapters, the concept of moral luck describes how actual outcomes affect moral judgments on decisions and actions, even when they are affected by factors beyond an agent's control (Nagel, 1979; Williams, 1981). Fear of moral luck can lead professionals on social media and in other settings to experience moral paralysis (Kvalnes, 2017), a reluctance to take any form of risk due to a perceived lack of protection against criticism and repercussions if the outcome of one's efforts should happen to be unwelcome or bad. In a social media context, leaders can prevent moral paralysis by being supportive of their employees when they engage in risky activities. Their commitment and support are put to the test when high-tempo experimentation actually causes harm, as in the Oktoberfest Instagram story outlined above. In that particular case, the leaders displayed ethical leadership by taking responsibility and providing adequate protection to the employees involved. Input from this study's informants indicates that ethical leadership of this kind is exceptional. They report an absence of such leadership, as leaders' self-interest apparently dominates over concern for what is best for an organization.

Leadership is put to the test in interactions between social media specialists and their leaders. Based on input to this study, it appears that the leaders tend to withdraw from challenges at hand and leave the responsibility to the social media professionals. Here is one example from the student memos:

We had a managerial vacancy in my organization and wanted to recruit internally. Three candidates applied for the position. One of the candidates who did not get the position thought that she had been treated unfairly and discriminated against based on gender. We have a male-dominated management group, and the candidate who got the job is a man. The woman who felt badly treated took out her frustration on her Facebook page and thereby reached a wide audience within and outside our organization. I received a message from top management requesting that I should talk to the employee and get her to delete the posts and find other ways of communicating her grievances. I was very uncomfortable with that request. Was it really my responsibility to address the issue with the employee? I am responsible for the social media accounts in our organization and know 
more about social media than the people in the management group do. Even so, you do not need to be a specialist in the workings of social media to explain to an employee that she has stepped over the line. To me, it seemed natural that her nearest manager should have that difficult conversation with her.

This example is one of several where the informants-people who run social media platforms for an organization-have felt that they are expected to step into leadership roles. They face role confusion and ultimately role dilemmas. Their main responsibility is to administer and optimize social media use for their organizations, but when human resources issues like the one described above occur, they are expected to take initiative there as well. The informants then typically respond with frustration, since they lack a formal leadership role. Taking on leadership responsibilities is not part of their job descriptions, and they do not have the authority to dispense specific instructions on ethical aspects of social media use. They may be in a position to say, "Your/my/our leader told me to tell you," but that in itself begs the question of why a leader is not present in the conversation.

Another typical situation is one where leaders push for a particular message to be published though an organization's social media but lack the expertise to judge the wisdom of doing so:

My leaders have different meanings about what we should publish digitally and are trying to promote their messages on social media. Everybody thinks that his or her message is the most important one. So far we have no strategy regarding what to publish, but I have a relatively good grasp of what works well and what does not work. Should I refuse my superiors to publish what I think would reflect badly on them and our organization, or let them publish whatever they want?

This situation seems to constitute a false dilemma, since it would be wrong to let the leaders publish whatever they want. It appears that social media professionals should intervene and stop social media use that could reflect poorly on the leader and the organization. However, in such cases, it is difficult and risky to do the ethically right thing because criticism of 
a leader's behavior on social media may not be a good career move. Regardless, leaders who insist on the primacy of their own messages fail to exemplify normatively appropriate conduct and as such fall short of the requirements of ethical leadership.

Ethical leaders are fair, honest and principled individuals who use various forms of rewards, punishments and communication mechanisms to influence their followers' ethical behavior. A range of studies have documented that ethical leadership tends to create positive follower outcomes (Bedi, Alpaslan, \& Green, 2016). Research has suggested that ethical leadership boosts psychological well-being and job satisfaction (Avey, Wernsing, \& Palanski, 2012) as well as trust (Brown et al., 2005), and that it decreases employees' propensity to morally disengage (Moore et al., 2019). Organizations thus have multiple reasons to recruit and develop people who can exercise ethical leadership.

The research on ethical leadership has suggested that much can be gained from promoting and displaying it and that there are corresponding downsides to its absence. One of the examples discussed under the heading of speech dilemmas in Chap. 2 can serve as an illustration of leadership that is lacking in ethical quality:

I am working for a public directorate. The minster has initiated dramatic changes in our procedures. One of my colleagues is very critical to these changes based on his expertise and experience. He uses Twitter to express his criticism of the minister's initiative and receives so much attention that even the non-digital management in the directorate gets to hear about it. Now they ask me, as a representative of the communications unit, to tell the colleague to stop using Twitter to express his critical views. How should I proceed?

This social media professional is understandably ill at ease at the prospect of being handed the responsibility to intervene in a colleague's Twitter use. It poses a role dilemma in that the professional feels that he and his management are operating from conflicting understandings of their designated roles. It also has an integrity dilemma dimension, as the agent would compromise his professional standards if he were to obey the order from management. The outspoken employee faced a speech 
dilemma-can I use Twitter in this manner? - and his decision creates a dilemma in the same category for the social media professional and his leaders. What are they entitled to say now, from an ethical point of view?

The situation is parallel to the one outlined at the beginning of the chapter, wherein an employee was using Facebook to complain about perceived unfair treatment in an internal recruitment process. Active and engaged leadership in neither case requires expertise in the specific workings of social media. The colleague's leader should be perfectly capable of addressing the issue with the employee, even without a grasp of how Twitter works. If the matter is considered to be serious, then surely the message should come from a leader. A leader who refuses to deliver the said message fails to engage in ethical leadership in terms of taking personal action and showing normatively appropriate behavior.

Many of the informants in this study express similar frustration over what can be deemed a lack of exemplary, ethical leadership from their superiors. The leaders typically push the responsibility for handling ethical dilemmas onto the social media professionals. The more overarching problem that informants report is a lack of resources for appropriate handling of ethical dilemmas. They are entering unfamiliar technological territory, where ethical navigation is difficult due to a number of factors:

1. Insufficient support from leaders, who tend to have restricted understanding of the workings of social media

2. A lack of established codes or norms

3. An absence of narratives about exemplary handlings of previous cases

4. Limited access to concepts and ideas that clarify the issues at stake

The current study offers potential for release from the first and last of these frustrations. The proposed categorization of dilemmas can serve to bring practitioners and their leaders closer together. It identifies the kinds of situations that can occur in connection with social media use in organizations and thus provides a common platform from which to draw up plans and strategies for handling them in a constructive manner. With the introduction of the Navigation Wheel and ethical principles, it also provides a common platform for reflection on the dilemmas. 
Ethical leadership does not require expertise in every professional dimension of what goes on in an organization. More specifically, a leader can act in a principled, honest and fair manner when a dilemma on social media occurs in an organization. Lack of detailed knowledge about the workings of Facebook or Twitter is no excuse for stepping back from potentially toxic situations, where a person or group handling social media communication for an organization is seeking support to resolve an ethical dilemma. One way to offer support can be to join in a discussion about alternative options, a systematic analysis whereby the participants seek out a solution together. If somebody within an organization is judged to have misused social media, it seems reasonable for a leader to address that misuse with the person involved and not delegate the responsibility to individuals in charge of social media accounts.

\section{Balanced Leadership}

The informants of this study report a recurring pattern of cases where a senior employee or leader has developed bad habits in using social media, either on behalf of the organization or in a capacity that can easily be associated with the organization. The impulsive and thoughtless posts on Facebook are there for all to see. The informants convey that in such situations, their leaders expect them - the social media experts - to address the issue with the employee or leader. The previous section discussed requests of this kind under the heading of ethical leadership, defined as a demonstration of normatively appropriate conduct through personal actions and interpersonal relationships. It argued that it is unreasonable of leaders to order social media professionals to step into their shoes to perform leadership tasks.

At first glance, it appears that leaders who delegate difficult conversations with employees about questionable Facebook use onto subordinates thereby neglect their leadership responsibilities. It seems reasonable to assume that a leader's responsibilities typically include handling human relations issues that arise from ethical aspects of social media use in the organization. Building up an understanding of the workings of social media should be an important priority for people with leadership 
ambitions in organizations where Facebook and other platforms are likely to be central to communication with stakeholders.

Another interpretation of the leadership behaviors reported in this study is that some of them are invitations to lead, rather than neglect of one's own responsibilities. The formal leaders appear to be inviting social media professionals to engage in distributed leadership (Spillane \& Diamond, 2007), as if they are saying, "Here is a critical situation at work, and now you can take the lead in resolving it." Such leaders provide professionals under their command with a scope of action for taking the lead. It is common to view leadership as an activity performed by one person-the leader-but it can also be useful to consider it as an ongoing activity executed between members of a team. In daily activities, the members can take turns being the leader. The distinction between vertical and horizontal leadership brings out this difference (Müller et al., 2018). In a range of organizational settings, the role of setting standards, motivating colleagues and keeping a project on track does not belong to one person who vertically oversees and manages the processes; instead, team members alternate on taking the lead. Studies on project management have identified the need to establish balanced leadership, which allows for vertical and horizontal leadership simultaneously (Müller et al., 2017).

The need for balanced leadership is evident in cases where ethical issues on social media occur within an organization and there are no formal leadership structures in place to address or resolve them. Somebody needs to take initiative, and social media professionals may not even be aware of the issue at hand. In such circumstances, an organization open to horizontal leadership is less vulnerable to mishaps, as it is normal for people other than the vertically placed leaders to intervene and attend to the matter at hand.

Social media creates a platform for rapid exchange of information, and as noted previously, this high tempo increases the likelihood of mishaps and blunders. If the person at the keyboard is also under the influence of alcohol or other substances, the probability of embarrassment is even higher. One informant described a situation where a senior, high-profile person in an organization was active on Twitter one Friday evening and appeared to be drunk. She was using rude and expressive language in dialogue with other Twitter users. Whose responsibility was it to take 
action and stop her from further embarrassing herself and the organization? This was a situation where somebody, either a fellow manager or someone lower in the organization, needed to take initiative to halt the turn of events. An organization depends on a scope of action for taking the lead beyond rank and hierarchy to cope with such situations.

One challenge obstructing positive outcomes to situations where a drunk representative of an organization is active on social media is the psychological phenomenon called the bystander effect (Darley \& Latané, 1968; Latané \& Darley, 1976). A diffusion of responsibility can occur when many people are witnesses to a critical situation. Furthermore, when many bystanders are present and people observe that nobody is taking action, that perception can lead to pluralistic ignorance-a sense that because others are passive, there is little cause for alarm (Beu, Buckley, \& Harvey, 2000; Zhu \& Westphal, 2011). For a discussion of the relevance of the bystander effect for ethics, see Kvalnes (2019).

These reflections on horizontal leadership as a supplement to vertical leadership are not meant as corrections to the frustrations of this study's informants, who have experienced leaders unreasonably pushing leadership responsibilities onto them. The informants' examples appear to come from organizations with vertical leadership structures, whereby it is the leaders' responsibility to discipline employees, even when they misbehave in a format and context on which the leader lacks adequate understanding. The point of discussing balanced leadership is rather to highlight that dilemmas stemming from social media use in organizations may be dealt with more adequately if horizontal structures are established as supplements to the more traditional, person-oriented, vertical structures.

Leadership in connection with social media is an area that deserves further attention from researchers and practitioners. Ethical dilemmas are among the key challenges that leaders and employees need to cope with together. The categorizations and analytical tools in this book provide a platform for doing so in a systematic manner, to avoid being solely reliant on fast and intuitive decision-making. 


\section{Doing Good and Avoiding Harm}

The aim of the final section of this book is to convey the breadth of issues that fall under the heading of ethics in the context of digital transformation and social media. Leaders and other decision-makers should be aware that ethics is concerned not only with avoiding harm, but also with doing good. In organizational ethics, people have been guilty of emphasizing the former at the expense of the latter. The do not's and the should not's have prevailed over the do's and should's. Researchers have noted this asymmetry and called for a more balanced presentation of ethical issues, one that clearly acknowledges that ethical concerns and responsibilities include both avoiding negative behaviors and outcomes and promoting positive ones (Carnes \& Janoff-Bulman, 2012; Janoff-Bulman et al., 2009; Sheikh \& Janoff-Bulman, 2010; Treviño et al., 2006).

Calls for a symmetrical view of ethics, giving attention to doing good and not just avoiding harm, have parallels in the domains of psychology and organizational studies. The emergence of positive psychology came as a response to decades of extensive research on anxiety and depression and of relatively little attention to joy and well-being. It generated a shift in attention from pathological psychological states to optimal ones (Seligman, 2002; Sheldon \& King, 2001). Similarly, positive organizational scholarship shifted the focus from conflict, stress, burnout and other negative aspects of working life to what characterizes organizations that nurture human strength and resilience in employees, make restoration and reconciliation possible and cultivate extraordinary individual and organizational performance (Cameron \& Dutton, 2003; Cameron, Dutton, \& Quinn, 2003; Dutton, 2003).

Organizational ethics has needed a similar change in focus, from the dark sides to the bright sides of human interaction and from the ways leaders and employees misbehave in organizational settings to how individual and collaborative efforts from prosocial motives can generate positive outcomes.

The distinction between do-good ethics and avoid-harm ethics is highly relevant in the context of social media. Here there is also a risk of emphasizing the avoidance aspects of ethics over the good things that can 
Table 4.1 Do-good and avoid-harm ethics issues in social media

\begin{tabular}{ll}
\hline Do-good ethics & Social media use should contribute to the following: \\
& - Empowerment \\
- Transparency & - Employee engagement \\
& - Sharing of knowledge \\
& - Driving positive change \\
& - Prosocial behavior \\
& Social media use should not contribute to the following: \\
& - Loss of integrity \\
- Horassment & - Discrimination \\
& - Trolling \\
& - Fake news \\
& - Destructive politics
\end{tabular}

come out of social media use in organizations. There are ethical traps one should avoid, by not posting certain kinds of content, not sacrificing one's integrity, not exploiting one's superior competence to trick a client and so on. A long list of such do not's and should not's can overshadow ethically positive uses of social media. An alternative starting point can be to list general ethical issues in the two domains (Table 4.1):

The items in these lists are preliminary suggestions for what could belong under the two headings, and more can be added to both categories. Emerging research has provided content for the positive ethical dimensions of social media. Ewing, Men, and O’Neil (2019) studied how internal use of social media in organizations can engage and empower employees. Social media create a platform for sharing knowledge within organizations (Havakhor, Soror, \& Sabherwal, 2018; Neeley \& Leonardi, 2018). Proper use of social media can help form smart organizations characterized by a free flow of information and shared knowledge (Nisar, Prabhakar, \& Strakova, 2019).

Positive and constructive aspects of organizational social media use are not normally placed under the heading of ethics. The phenomena may be acknowledged but are not framed as having anything to do with ethics in a given organization. However, the shift in attention within organizational ethics suggests that these beneficial aspects belong in that framework when taking stock of the ethical dimensions of social media. Habits 
and patterns of understanding ethics primarily through avoidance of negative behaviors and outcomes are hard to dispel. Their source may be the general phenomenon of negativity bias, which is the human propensity to give more attention to the negative aspects of bad outcomes than to the positive aspects of good outcomes (Tversky \& Kahneman, 1991; Vaish, Grossmann, \& Woodward, 2008). The negativity pattern is present even in the informants' input. They were not introduced to the difference between do-good ethics and avoid-harm ethics in advance of making their contributions, and a pattern emerges in the material of seeing that their ethical challenges mainly involve avoidance of negative behaviors and outcomes. This can be regarded as a limitation of the study. Giving the students directions on the difference between the two ethics types and how organizational ethics encompasses both may have provided more variation and breadth in their input, as well as material for a more symmetrical account of ethical dilemmas in handling organizations' social media platforms.

Future studies of ethical dilemmas in social media use can incorporate the distinction between do-good ethics and avoid-harm ethics. On a general note, it seems that ethical dilemmas can materialize when a decisionmaker must prioritize between two possible positive outcomes or when the only way to reach a positive outcome appears to be through behaviors that are negative. Many ethical do-good projects can be pursued without creating conflict by either of these considerations. In such ethically harmonious and tension-free circumstances, constructive use of social media can energize an organization and bring about positive change.

This final chapter has connected ethics on social media to leadership. The opening example was one where posting provocative photos on Instagram led to public criticism of a bank. The leadership intervened in what appeared to be an ethically exemplary manner, by protecting the employees who had posted the photos and taking responsibility. Input to the current study indicates that leaders in organizations struggle to cope with the ethical challenges raised by social media use. Many of the informants have expressed frustration over a lack of leadership support in dealing with ethical dilemmas. What they have found wanting can be labeled ethical leadership, which is understood as normatively appropriate behavior based on personal actions and interpersonal relationships. From the 
informants' perspectives, their leaders have not been sufficiently present as principled, honest and fair supporters when ethical dilemmas have occurred. The examples seem to have come from organizations with predominantly vertical leadership structures, and one remedy suggested here has been to introduce horizontal leadership, which takes place between members of a team. Under such leadership, the responsibilities to intervene, offer support and raise critical questions lie with each member. Balanced leadership happens when there is a combination of vertical and horizontal leadership in an organization. Constructive development of social media use in an organization seems to depend on the presence of horizontal leadership, either as the main way of leading or in tandem with vertical leadership.

The final section presented the distinction between do-good ethics and avoid-harm ethics as crucial for developing symmetrical organizational ethics and mapping the breadth of ethical issues produced by social media. This distinction is necessary to acknowledge the ethically positive aspects of social media.

Inspiration to write this book came from encounters with engaged practitioners whose day-to-day working lives consist of administrating social media accounts on behalf of their organizations. Over a period of five years, executive students who belong to this category of employees have generously shared their experiences and allowed their memos to form the data for this study. From the outset, the ambition of the book has been to come up with a theory that can be of use to practitioners. The categorization and cognitive tools conveyed in it can support and enhance ethically responsible decision-making and behavior in the use of social media. The book thus reaches out to practitioners with organizational roles similar to the ones of those who have contributed to the study. Fellow academics may also find elements here that they would like to expand on and elaborate further in the name of research. 


\section{References}

Avey, J. B., Wernsing, T. S., \& Palanski, M. E. (2012). Exploring the process of ethical leadership: The mediating role of employee voice and psychological ownership. Journal of Business Ethics, 107(1), 21-34.

Bedi, A., Alpaslan, C. M., \& Green, S. (2016). A meta-analytic review of ethical leadership outcomes and moderators. Journal of Business Ethics, 139(3), 517-536.

Beu, D. S., Buckley, M. R., \& Harvey, M. G. (2000). The role of pluralistic ignorance in the perception of unethical behavior. Journal of Business Ethics, 23(4), 353-364.

Brown, M. E., Treviño, L. K., \& Harrison, D. A. (2005). Ethical leadership: A social learning perspective for construct development and testing. Organizational Behavior and Human Decision Processes, 97(2), 117-134.

Cameron, K., \& Dutton, J. (2003). Positive organizational scholarship: Foundations of a new discipline. San Francisco, CA: Berrett-Koehler Publishers.

Cameron, K., Dutton, J., \& Quinn, R. (2003). An introduction to positive organizational scholarship. Positive organizational scholarship, 3, 13.

Carnes, N., \& Janoff-Bulman, R. (2012). Harm, help, and the nature of (im) moral (in) action. Psychological Inquiry, 23(2), 137-142.

Darley, J. M., \& Latané, B. (1968). Bystander intervention in emergencies: Diffusion of responsibility. Journal of Personality and Social Psychology, 8(4), 377-383.

Dutton, J. (2003). Energize your workplace: How to create and sustain high-quality connections at work. New York: John Wiley \& Sons.

Ewing, M., Men, L. R., \& O’Neil, J. (2019). Using social media to engage employees: Insights from internal communication managers. International Journal of Strategic Communication, 13(2), 110-132.

Havakhor, T., Soror, A. A., \& Sabherwal, R. (2018). Diffusion of knowledge in social media networks: Effects of reputation mechanisms and distribution of knowledge roles. Information Systems Journal, 28(1), 104-141.

Janoff-Bulman, R., Sheikh, S., \& Hepp, S. (2009). Proscriptive versus prescriptive morality: Two faces of moral regulation. Journal of Personality and Social Psychology, 96(3), 521.

Kvalnes, Ø. (2017). Fallibility at work: Rethinking excellence and error in organizations. London: Palgrave Macmillan.

Kvalnes, Ø. (2019). Moral reasoning at work: Rethinking ethics in organizations (2nd ed.). London: Palgrave Macmillan. 
Latané, B., \& Darley, J. M. (1976). Help in a crisis: Bystander response to an emergency. Morriston, NJ: General Learning Press.

Mayer, D. M. (2010). From proscriptions to prescriptions: A call for including prosocial behavior in behavioral ethics. In Managerial ethics. Managing the psychology of morality (pp. 257-269). New York: Routledge.

Moore, C., Mayer, D. M., Chiang, F. F., Crossley, C., Karlesky, M. J., \& Birtch, T. A. (2019). Leaders matter morally: The role of ethical leadership in shaping employee moral cognition and misconduct. Journal of Applied Psychology, 104(1), 123.

Müller, R., Packendorff, J., \& Sankaran, S. (2017). Balanced leadership: A new perspective for leadership in organizational project management. In S. Sankaran, R. Müller, \& N. Drouin (Eds.), Cambridge handbook of organizational project management. Cambridge: Cambridge University Press

Müller, R., Sankaran, S., Drouin, N., Vaagaasar, A.-L., Bekker, M. C., \& Jain, K. (2018). A theory framework for balancing vertical and horizontal leadership in projects. International Journal of Project Management, 36(1), 83-94.

Nagel, T. (1979). Moral luck. In Mortal questions. Cambridge: Cambridge University Press.

Neeley, T. B., \& Leonardi, P. M. (2018). Enacting knowledge strategy through social media: P assable trust and the paradox of nonwork interactions. Strategic Management Journal, 39(3), 922-946.

Neubert, M. J., Carlson, D. S., Kacmar, K. M., Roberts, J. A., \& Chonko, L. B. (2009). The virtuous influence of ethical leadership behavior: Evidence from the field. Journal of Business Ethics, 90(2), 157-170.

Nisar, T. M., Prabhakar, G., \& Strakova, L. (2019). Social media information benefits, knowledge management and smart organizations. Journal of Business Research, 94, 264-272.

Seligman, M. E. (2002). Positive psychology, positive prevention, and positive therapy. Handbook of positive psychology, 2(2002), 3-12.

Sheikh, S., \& Janoff-Bulman, R. (2010). The "shoulds" and "should nots" of moral emotions: A self-regulatory perspective on shame and guilt. Personality and Social Psychology Bulletin, 36(2), 213-224.

Sheldon, K. M., \& King, L. (2001). Why positive psychology is necessary. American Psychologist, 56(3), 216.

Spillane, J. P., \& Diamond, J. B. (2007). Distributed leadership in practice. New York: Teachers College, Columbia University.

Treviño, L. K., Weaver, G. R., \& Reynolds, S. J. (2006). Behavioral ethics in organizations: A review. Journal of Management, 32(6), 951-990. 
Tversky, A., \& Kahneman, D. (1991). Loss aversion in riskless choice: A reference-dependent model. The Quarterly Journal of Economics, 106(4), 1039-1061.

Vaish, A., Grossmann, T., \& Woodward, A. (2008). Not all emotions are created equal: The negativity bias in social-emotional development. Psychological Bulletin, 134(3), 383.

Williams, B. (1981). Moral luck: Philosophical papers 1973-1980. Cambridge: Cambridge University Press.

Zhu, D. H., \& Westphal, J. D. (2011). Misperceiving the beliefs of others: How pluralistic ignorance contributes to the persistence of positive security analyst reactions to the adoption of stock repurchase plans. Organization Science, 22(4), 869-886.

Open Access This chapter is licensed under the terms of the Creative Commons Attribution 4.0 International License (http://creativecommons.org/licenses/ by/4.0/), which permits use, sharing, adaptation, distribution and reproduction in any medium or format, as long as you give appropriate credit to the original author(s) and the source, provide a link to the Creative Commons licence and indicate if changes were made.

The images or other third party material in this chapter are included in the chapter's Creative Commons licence, unless indicated otherwise in a credit line to the material. If material is not included in the chapter's Creative Commons licence and your intended use is not permitted by statutory regulation or exceeds the permitted use, you will need to obtain permission directly from the copyright holder.

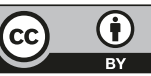

